\title{
Sterol and Bile Acid Excretion in Man and the Effects of Dietary Fat *
}

\author{
Joel Avigax † and Daniel Steinberg with the technical assistance of \\ Hugh VROMAN $\ddagger$
}

(From the Laboratory of Metabolism, National Heart Institute, Bethesda, Md.)

It is now well established that diets rich in saturated fatty acids lead to high levels of serum cholesterol, whereas diets rich in unsaturated fatty acids tend to be associated with lower levels. The mechanism by which these changes in serum cholesterol are induced by dietary fat is not known. One possible explanation for these effects would be either inhibition of cholesterol biosynthesis by unsaturated fats or stimulation of synthesis by saturated fats. The effects on synthesis, if any, could, in turn, be either the result of a direct action of the dietary fat on the biosynthetic system or of a secondary adjustment to any change in the rate of oxidation and excretion of cholesterol and its metabolites. Alternatively, changes in dietary fat might not affect the turnover rate, but cause a shift of part of the serum cholesterol pool, either from or into tissue compartments.

Finally, the changes in serum cholesterol might reflect a primary effect not on sterol metabolism per se, but on the metabolism of lipoproteins, direct or mediated through effects on the metabolism of one or several of the moieties making up the macromolecule. These might act singly or in combination.

In the present studies we have administered cholesterol- $4-{ }^{-14} \mathrm{C}$ to subjects fed liquid formula diets containing saturated or unsaturated fat and subsequently measured the specific radioactivity of plasma cholesterol as a function of time. Simultaneously, the fecal excretion of sterol and bile acid was measured by a radioactivity balance method.

* Submitted for publication May 3, 1965 ; accepted July 2, 1965.

A preliminary report of these results has been published (1).

† Address requests for reprints to Dr. Joel Avigan, Laboratory of Metabolism, National Heart Institute, Bethesda, Md. 20014.

¥ Present address : Insect Physiology Laboratory, U. S. Department of Agriculture, Agriculture Research Center, Beltsville, Md.

\section{Methods}

Each of the six subjects was admitted to the Clinical Center of the National Institutes of Health for the full period of his study. After preliminary observation on a regular diet, during which the caloric requirement to maintain admission weight was established, some subjects were started on a liquid formula diet (2) providing $60 \%$ of total calories in the form of fat, $15 \%$ as protein, and $25 \%$ as carbohydrate. Coconut oil was used as the saturated fat in all studies. Unsaturated fat in some studies was provided as corn oil. In other studies a special sterol-poor preparation of ethyl esters of fatty acids derived from safflower oil (iodine no. 138.5) was used. ${ }^{1}$ The formula was supplemented only with iron, vitamins, cellulose wafers, and black coffee or tea. Except for some transient looseness of stool during the first few days on formula and the anticipated impatience with dietary monotony, patients were maintained over periods of weeks to months on this regimen without complication or complaint.

After at least 2 weeks on a given formula, patients received approximately $5 \mu \mathrm{c}$ of cholesterol-4- ${ }^{14} \mathrm{C}$ intravenously. By this time, a stable level of serum cholesterol had been reached. The labeled cholesterol was given in the form of a complex with the patient's own serum prepared by the method of Avigan (3). An ether solution of cholesterol-4- ${ }^{14} \mathrm{C}$ was added to powdered Celite and the solvent allowed to evaporate. A sample of 5 to 10 $\mathrm{ml}$ of the patient's serum was then incubated under sterile conditions with this cholesterol-coated Celite for 16 hours at $37^{\circ} \mathrm{C}$ with gentle shaking. It has been shown that $97 \%$ of the label incorporated into human serum in this fashion is bound in the lipoprotein fractions (3). After ultrafiltration, pyrogen testing, and radioassay, the appropriate sample of labeled serum was administered intravenously. No reactions were encountered. Two to 3 weeks after the administration of the cholesterol $-{ }^{14} \mathrm{C}$, the type of dietary fat in the formula was changed, and observations were continued for at least another 2-week period.

Total serum cholesterol was determined at least twice weekly (4). Serum phospholipids (5) and triglycerides (6) were determined after the serum cholesterol level had stabilized during each dietary period. After administration of the labeled cholesterol, serum cholesterol specific

\footnotetext{
1 Generously provided by Dr. F. H. Mattson of the Procter and Gamble Co.
} 
radioactivity was determined daily. The latter was calculated by dividing total radioactivity extracted with $1: 1$ alcohol-acetone by the net amount of cholesterol determined on another sample.

Total feces were collected directly into 1-gallon paint cans (7) over 48 -hour or 96 -hour collection periods, but in this report results of two 2-day collections were pooled to show an average of 4-day periods. Feces were dried in the collection cans on a steam bath, and the dry residue was powdered by shaking the sealed can containing some steel washers on a paint-shaking machine. The powder was weighed and stored at $4^{\circ} \mathrm{C}$ pending analysis. One-g samples were autoclaved 3 hours at $120^{\circ} \mathrm{C}$ with $2 \mathrm{~N}$ $\mathrm{NaOH}$. After addition of $75 \mathrm{ml}$ of $30 \%$ ethanol, the nonsaponifiable fraction (NSF) was extracted three times from the alkaline mixture with $60 \mathrm{ml}$ heptane. The combined heptane extracts were backwashed with water. The remaining aqueous phase was then adjusted to $\mathrm{pH} 2$ by addition of $\mathrm{HCl}$ and the saponifiable fraction (SF) extracted three times with $100 \mathrm{ml}$ of diethyl ether. The pooled ether extracts were backwashed with a small volume of water. Both the NSF and SF were taken to dryness and redissolved in methyl Cellosolve. Samples were dried on planchets with a series of concentric grooves that improve evenness and reproducibility of plating. All radioassays were carried out with a gas-flow counter equipped with a $0.2 \mathrm{mg}$ per $\mathrm{cm}^{2}$ window. Self-absorption correction factors were determined by adding cholesterol-
$4-{ }^{14} \mathrm{C}$ or bile acids $-{ }^{14} \mathrm{C}$ to various amounts of extracts of nonradioactive feces and counting in the same fashion.

Method of calculation of net sterol and bile acid excretion. Since the 4-carbon of cholesterol is not metabolized to any significant extent to $\mathrm{CO}_{2}(8)$, all the metabolic products are excreted in feces in the form of nonsaponifiable lipids and bile acids. The method employed is similar to that used by Hellman, Rosenfeld, Insull, and Ahrens $(9,10)$ and is based on the fact that the fecal end products have specific radioactivities that closely parallel that of the serum cholesterol. This was verified in the present study as shown in Figure 1. The values for sterol represent specific radioactivities of digitonin-precipitable material prepared from the NSF described above. All but one determination of fecal sterol specific radioactivity were done on samples collected while the patient was receiving the formula containing coconut oil, known to be quite poor in plant sterols. The small amounts of the latter ingested with the diet did not reduce appreciably the specific radioactivity of fecal sterols. The values for bile acids were those of deoxycholic acid isolated from fecal SF by reverse-phase chromatography on Celite columns according to the method of Mosbach, Zomzely, and Kendall (11). Before chromatography it was necessary to remove fatty acids by partition between $70 \%$ aqueous methanol and heptane. The specific radioactivities of the fecal end products examined paralleled the specific radioactivity of serum cholesterol. If it is

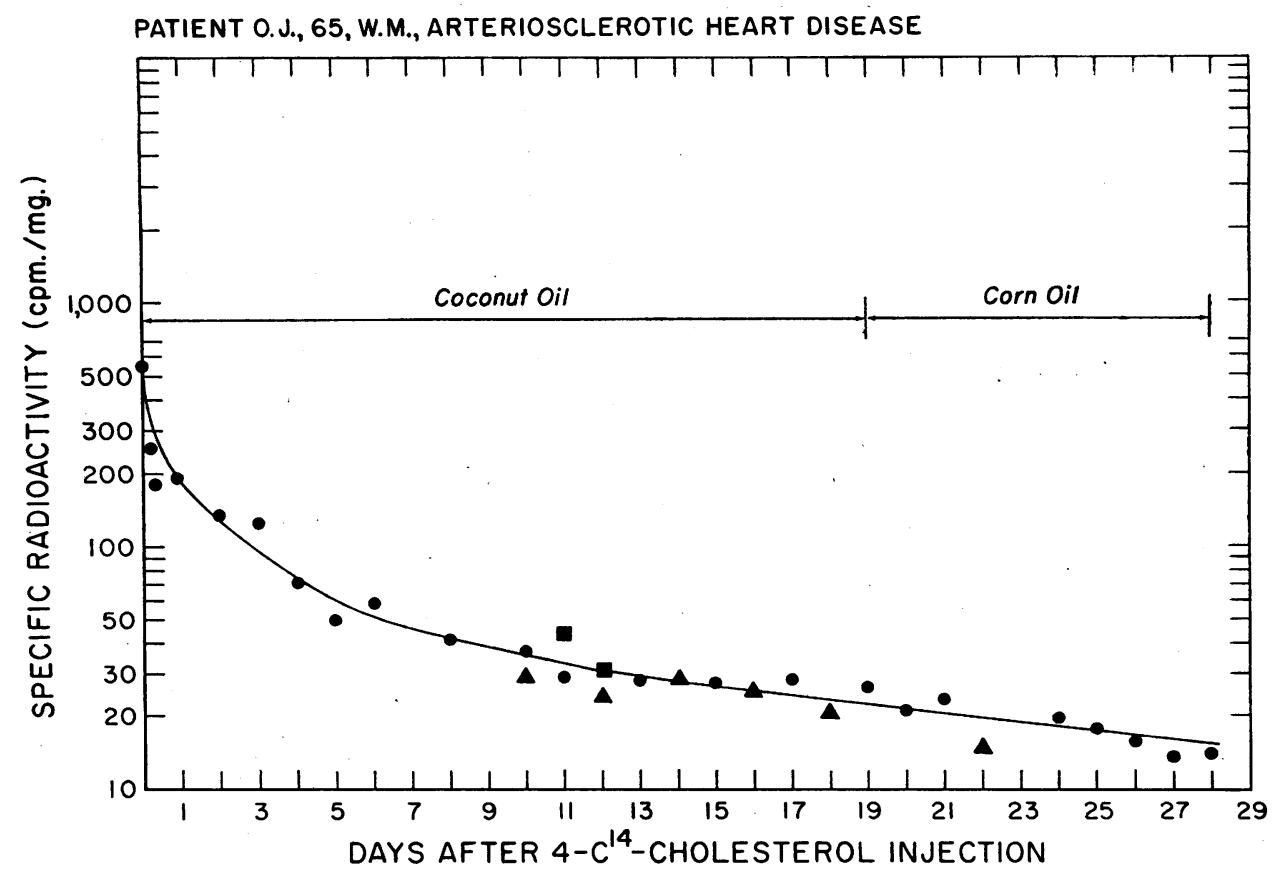

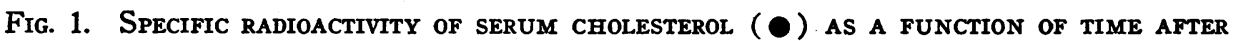
INTRAVENOUS INJECTION OF CHOLESTEROL-4- ${ }^{14}$ C-LABELED SERUM IN A REPRESENTATIVE CASE. The specific radioactivities of fecal digitonin-precipitable sterol $(\Delta)$ and of fecal deoxycholic acid (घ) are shown to parallel that of the serum cholesterol. 
assumed that the specific radioactivities of other fecal metabolites of cholesterol also follow the serum cholesterol curve in this fashion, the net excretion can be calculated from the total radioactivity excreted and the serum cholesterol specific radioactivity: total radioactivity in fecal fraction (counts per minute)/specific radioactivity of serum cholesterol (counts per minute per milligram) $=$ net end-product excretion expressed as cholesterol (milligrams). The serum cholesterol specific radioactivity used for calculations was that obtained 48 hours before the close of each fecal collection period.

According to Lindstedt (12), when labeled cholesterol is administered to man, the biliary cholic acid reaches the specific activity of serum cholesterol after a time lag of 4 to 5 days, whereas deoxycholic acid equilibrates only after 8 to 10 days. Had this slower equilibration of secondary bacterial metabolites also been true for our subjects, the calculated amounts of bile acids excreted during the first two fecal collections after administration of label should have been too low. Such a systematic trend was not observed, however. The presence of fatty acids, or other nonradioactive components in the SF should not
TABLE I

Reproducibility of methods for extraction and radioassay of nonsaponifiable and saponifiable lipid fractions

\begin{tabular}{ccc}
\hline $\begin{array}{c}\text { Sample } \\
\text { of dried } \\
\text { feces* }\end{array}$ & $\begin{array}{c}\text { Nonsaponifiable } \\
\text { lipid radio- } \\
\text { activity }\end{array}$ & $\begin{array}{c}\text { Saponifiable } \\
\text { lipid radio- } \\
\text { activity }\end{array}$ \\
\hline & $c p m$ & $c p m$ \\
$\mathrm{~A}$ & 952 & 126 \\
$\mathrm{~B}$ & 819 & 121 \\
$\mathrm{C}$ & 881 & 134 \\
$\mathrm{D}$ & 862 & 135 \\
Mean $\pm \mathrm{SE}$ & $878 \pm 28$ & $129 \pm 3.3$ \\
\hline
\end{tabular}

* Nonsaponifiable lipids were extracted from 500-mg samples, saponifiable lipids from 200 -mg samples.

interfere with calculation of net bile acid excretion. Similarly, the plant sterols, when present in the diet and isolated with the NSF, would not influence the calculated endogenous sterol excretion, since the sterols contributed no radioactivity.

The completeness of extraction of fecal sterols and bile acids was checked in several ways:

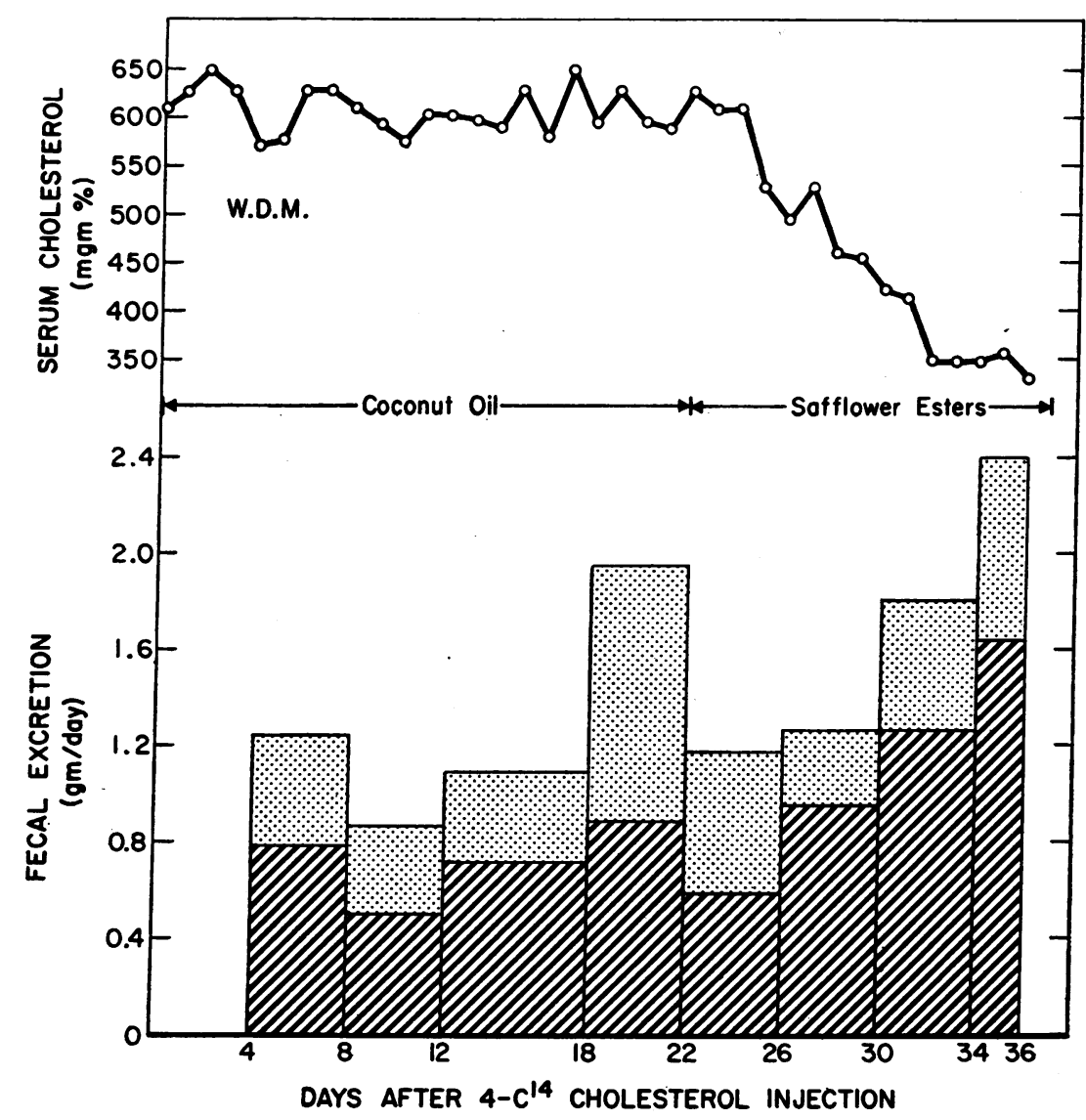

Fig. 2. Serum cholesterol concentration and Calculated fecal excretion OF NONSAPONIFIABLE CHOLESTEROL METABOLITES AND BILE ACIDS ON LIQUID FORMULA DIETS CONTAINING SATURATEd AND UNSATURATED Fat. Cross-hatched bar areas: fecal nonsaponifiables. Shaded bars: fecal bile acids. 


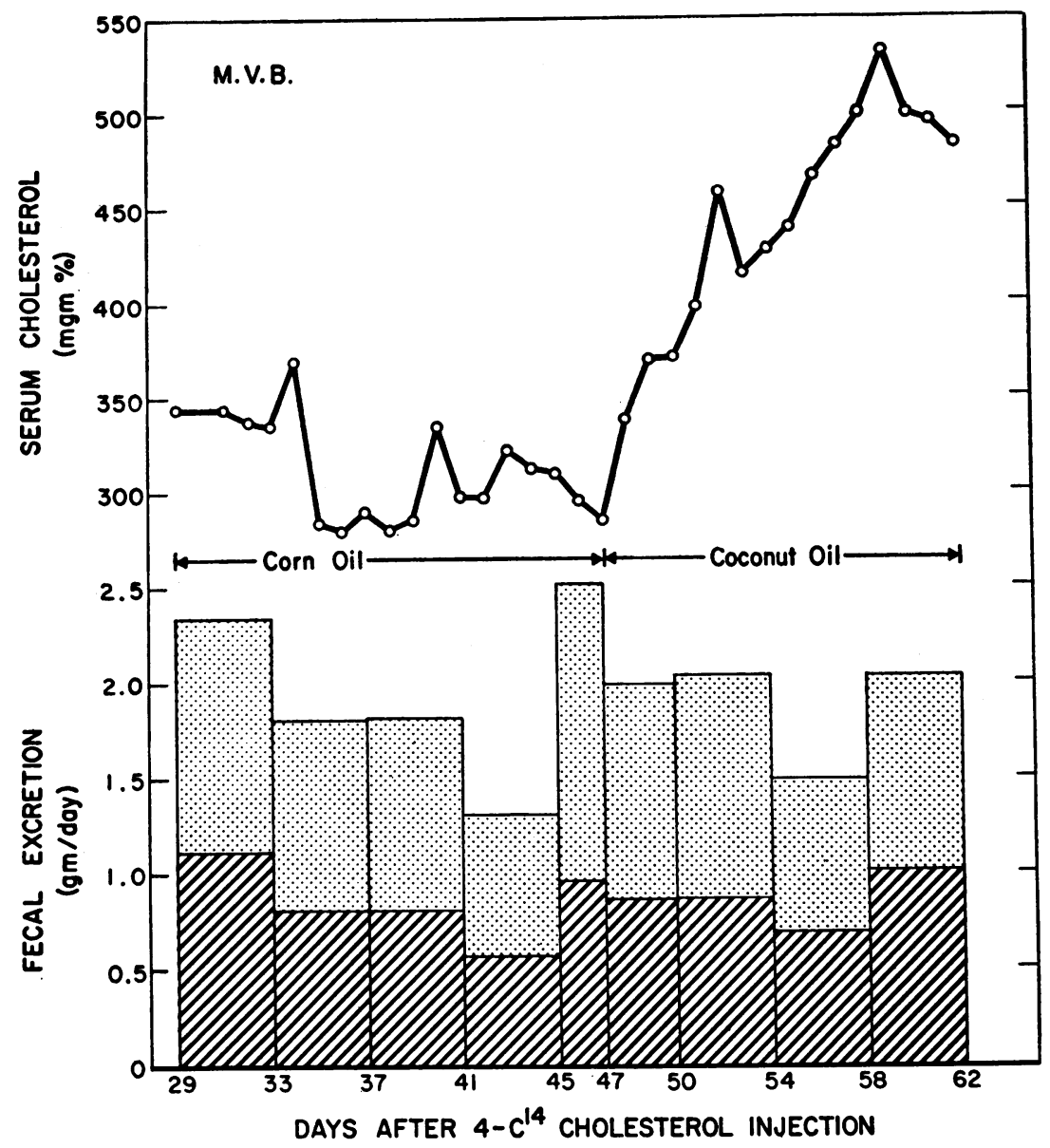

Fig. 3. SEe Legend to Figure 2.

First, the total radioactivity, as determined by counting dried feces, was compared with total carbon radioactivity determined by wet combustion of an equal portion and counting of ${ }^{14} \mathrm{CO}_{2}$ in Hyamine-DPO-toluene in a liquid scintillation counter. The radioactivities determined by end-window counting of three different solid samples were $98 \%, 106 \%$, and $107 \%$, respectively, of the radioactivities determined on ${ }^{14} \mathrm{CO}_{2}$ by wet combustion of these samples.

Second, the completeness of extraction of nonsaponifiable radioactive material was checked by counting samples of five successive heptane extracts of the alkaline saponification mixture. These contained: $20,056,260,92,38$, and $27 \mathrm{cpm}$, respectively. Thus, of the total radioactivity extracted, $97.2 \%$ was recovered in the first three extractions. After acidification, the radioactivity recovered in five successive ether extractions was 18,720, 2,671, 441, 158, and $64 \mathrm{cpm}$, respectively. Thus of the total radioactivities extracted, $99.0 \%$ was recovered in the first three extractions.

Third, the reproducibility of recovery of nonsaponifiable and saponifiable material was checked gravimetrically and isotopically. For quintuplicate samples of dried feces the recoveries in milligrams were, for nonsaponifiable lipids, $11.0 \pm 0.14$ (SE); for saponifiable lipids, $41.4 \pm 0.47$ (SE). Reproducibility of racioisotope recoveries is shown by the replicate analyses of a single fecal sample shown in Table I. Other measurements, not shown here, revealed that the main contributory factors to the relatively small standard error of radioactivity determinations (Table I) were irregularities of the planchets and other counting errors.

Finally, the recoveries of cholesterol-4- ${ }^{14} \mathrm{C}$ and of cholic acid-24- ${ }^{-1} \mathrm{C}$ added to nonradioactive feces were determined. Recoveries ranged from 85 to $90 \%$.

For statist.cal evaluation of diet-induced changes, variance was computed separately for the saturated fat period and the unsaturated fat period. The difference between the means was then evaluated for significance by the standard $t$ test.

\section{Results}

Complete data for serum cholesterol levels and for calculated fecal bile acid and sterol excretion 
in six subjects are presented in Figures 2 through 7. All subjects showed significantly lower serum cholesterol levels when on the unsaturated fat. The response to changing dietary fat occurred quite rapidly, a new steady-state level being reached generally within 10 to 14 days. It should be noted that the safflower ester preparation, which contained only $0.1 \%$ nonsaponifiable lipids, was highly effective in lowering serum cholesterol levels.

The specific radioactivity of serum cholesterol, determined at 1 - to 3-day intervals from the time of injection of cholesterol-4- ${ }^{14} \mathrm{C}$, fell rapidly at first and then more slowly. The curve shown in Figure 1 is representative of the results obtained. There was no apparent break in the curve on changing dietary fat (except in the case of subject W.D.M., where the serum cholesterol specific

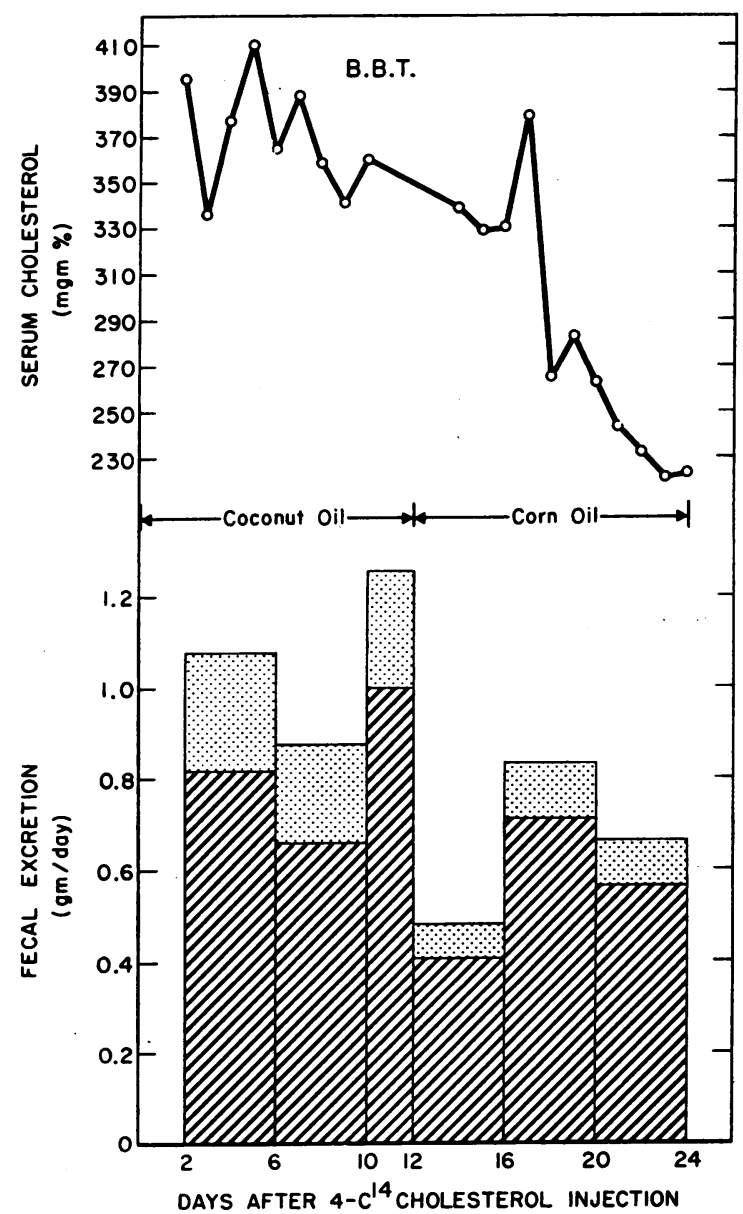

Fig. 4. See legend to Figure 2. radioactivity rose slightly during the fall of serum cholesterol level and then turned down again).

The partition of fecal radioactivity between SF and NSF was relatively constant in any given patient throughout his study, but there was considerable variation from patient to patient (Table II). In one case (B.B.T.), over $75 \%$ of the label recovered was found in NSF, whereas in two other cases (O.A.J. and W.F.B.) less than one-third was found in this form. The fraction of radioactivity excreted in NSF was somewhat greater on unsaturated fat (an average of $69.8 \%$ versus $47.7 \%$ on saturated fat). The considerable output of NSF radioactivity in feces contrasts with the small contribution of sterol radioactivity to the total found in bile by Siperstein and Murray (13). Ancillary to the present studies the excretion of radioactivity in bile was determined in one patient undergoing biliary T-tube drainage. Bile samples were taken at 2-day intervals for 8 days after administration of the labeled cholesterol. Here bile acids contained 87 to $95 \%$ of the total radioactivity recovered, in agreement with the results of Siperstein and Murray (13).

Even when serum cholesterol level was stable on a given formula diet, there was considerable variation in calculated absolute excretion of both sterols and bile acids in each of the subjects, even though the results were averaged for 4-day periods (see Figures 2 to 7 ). This variability was far greater than the variability due to the methods used (see Results and Table I). Although total labeled end-product excretion varied widely from collection to collection, the fraction of label recovered as sterol was much more constant, as can be seen from the small standard errors in Table II.

Total end-product excretion on the saturated-fat diet in five of the six subjects ranged between 1 and $2 \mathrm{~g}$ daily (mean, 1.52). The sixth subject (C.M.B.), however, showed a total daily endproduct excretion of $3.4 \mathrm{~g}$ on the saturated-fat diet and $5.3 \mathrm{~g}$ on the unsaturated-fat diet.

Total end-product excretion on the unsaturatedfat diet was lower than that on saturated fat in three cases and higher in the other three. If the 4-day averages in each diet period are treated as individual data, the mean for the unsaturated-fat period was significantly higher at the $p<0.05$ level only in subject C.M.B., but significantly lower in subjects B.B.T. and W.F.B. 


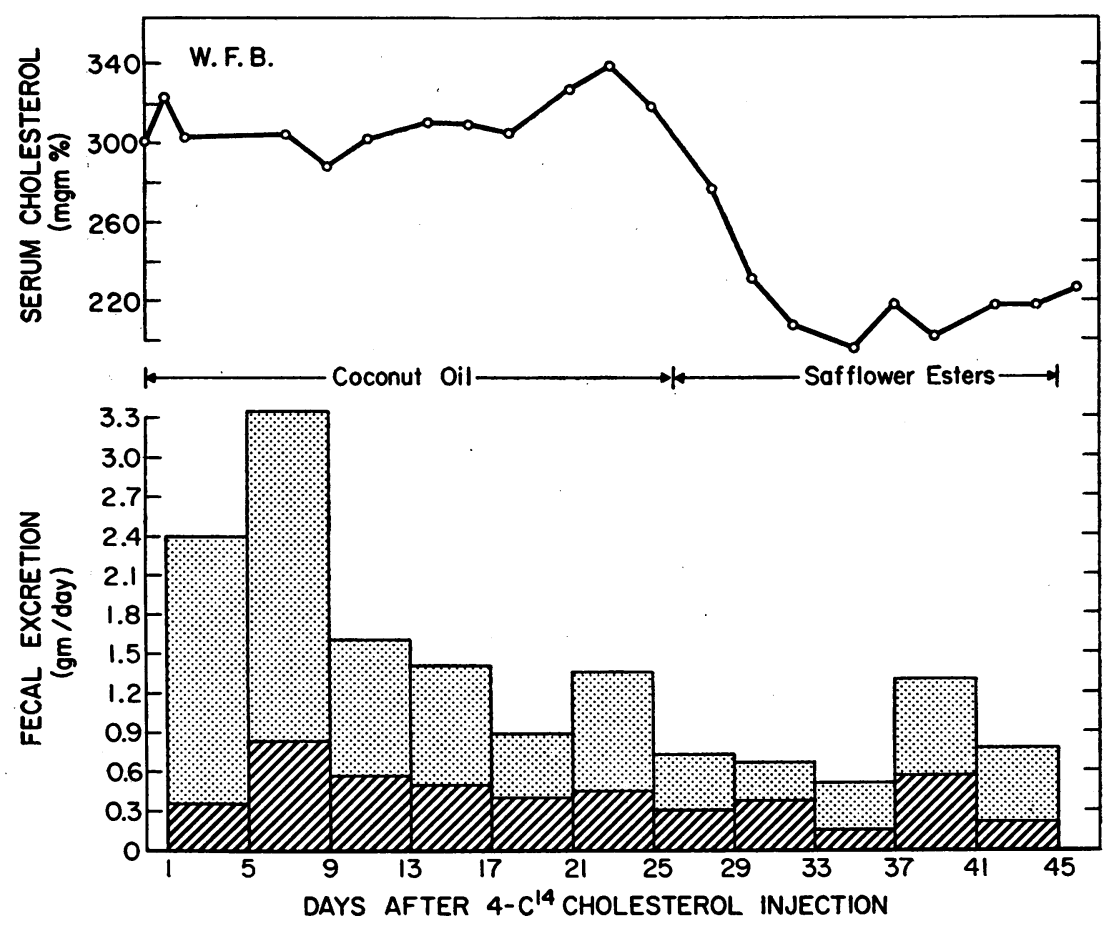

Fig. 5. See legend to Figure 2.

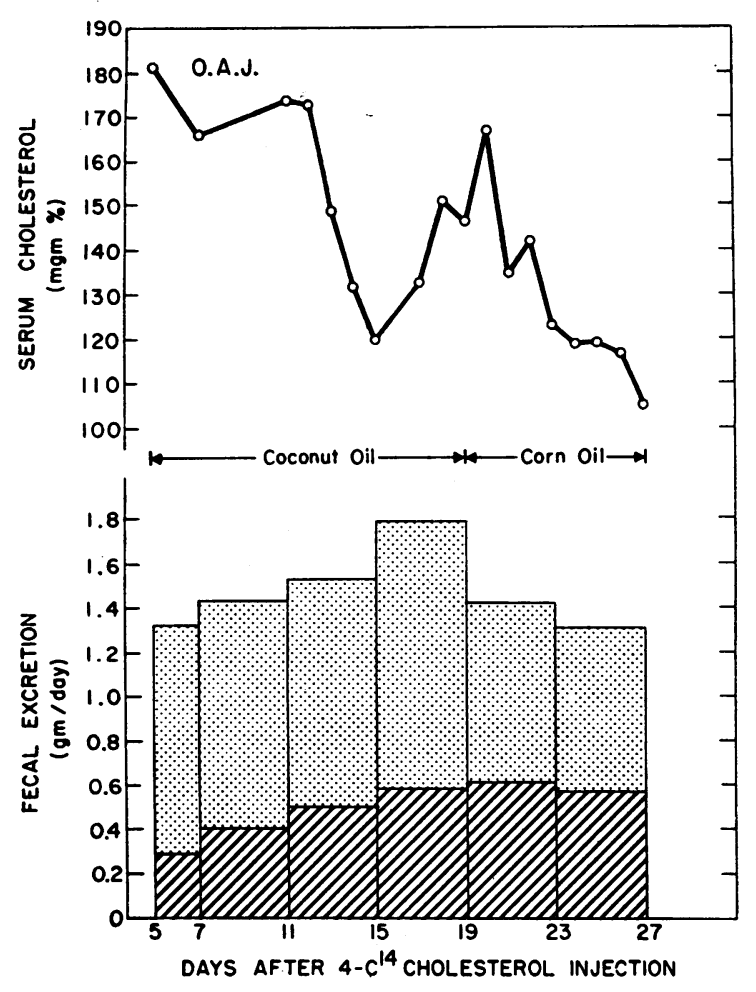

Fig. 6. See legend to Figure 2.
Bile acid excretion on the saturated-fat diet in five of the six subjects ranged from 0.24 to $1.27 \mathrm{~g}$ daily (mean, 0.79 ). In two subjects bile acid excretion was slightly higher and in three subjects lower on unsaturated fat. The sixth subject (C.M.B.) showed a bile acid excretion of $2.20 \mathrm{~g}$ on saturated fat and $2.32 \mathrm{~g}$ on unsaturated fat.

Sterol excretion on the saturated-fat diet in the five subjects ranged from 0.44 to $1.05 \mathrm{~g}$ daily (mean, 0.73). In three subjects sterol excretion was higher and in two lower on unsaturated fat. The sixth subject (C.M.B.) showed a truly remarkable rise in sterol excretion on unsaturated fat ( $2.97 \mathrm{~g}$ daily versus $1.24 \mathrm{~g}$ daily on saturated fat).

There was no obvious relationship between the magnitude of changes in serum cholesterol level on the one hand and changes in fecal end-product excretion on the other (Table III). Serum cholesterol in subject W.D.M. fell just as markedly as it did in subject C.M.B., but in the former the changes in end-product excretion were small and, in view of the variability from collection to collection, not statistically significant. Serum cholesterol in subject M.V.B. fell $175 \mathrm{mg}$ per $100 \mathrm{ml}$, but 


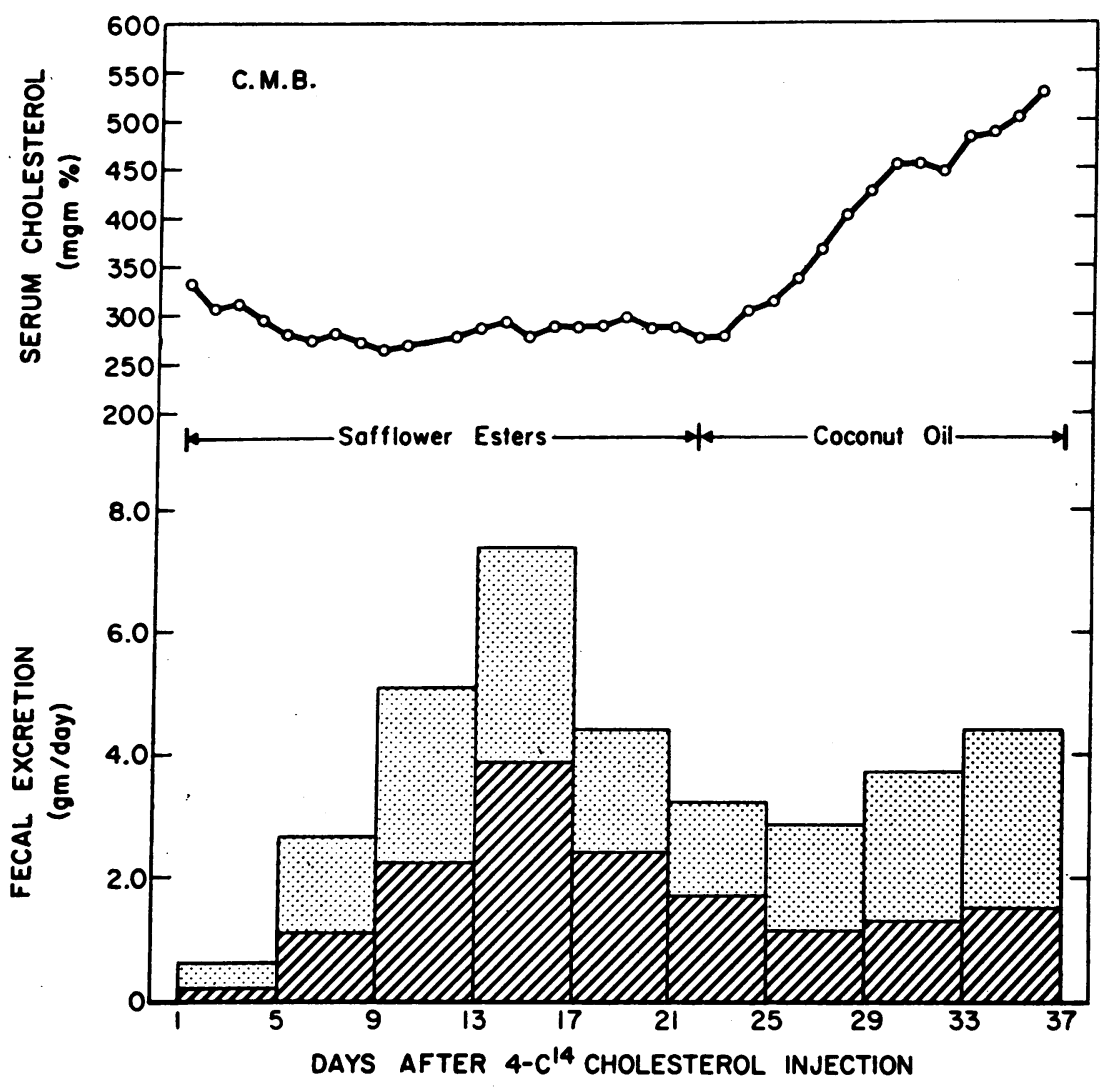

Fig. 7. SeE Legend to Figure 2.

there was no significant change in either bile acid or sterol excretion. Subjects B.B.T. and W.F.B. actually decreased their rate of end-product excretion on the unsaturated fat diet.

In subject C.M.B., the only one showing a large increase in end-product excretion on the unsaturated fat diet, the increase was almost exclusively in the NSF. In this respect, the results in this subject are similar to those in the single case reported by Hellman and co-workers $(9,10)$.

\section{Discussion}

The results show that excretion of NSF, consisting mostly of sterols, can account for a very large fraction of the fecal end products of cholesterol. There was considerable variation from

TABLE II

Fecal end-product excretion during saturated fat and unsaturated fat periods*

\begin{tabular}{|c|c|c|c|c|c|c|c|c|c|c|}
\hline \multirow[b]{2}{*}{ Subjects } & \multicolumn{5}{|c|}{ Saturated fat period } & \multicolumn{5}{|c|}{ Unsaturated fat period } \\
\hline & $\begin{array}{l}\text { No. of } \\
\text { collec- } \\
\text { tions }\end{array}$ & $\begin{array}{l}\text { Total end- } \\
\text { product } \\
\text { excretion } \\
( \pm S E)\end{array}$ & $\begin{array}{l}\text { Bile } \\
\text { acids }\end{array}$ & Sterols & $\begin{array}{l}\text { Sterols as } \\
\text { percentage } \\
\text { of total } \\
( \pm S E)\end{array}$ & $\begin{array}{l}\text { No. of } \\
\text { collec- } \\
\text { tions }\end{array}$ & $\begin{array}{c}\text { Total end- } \\
\text { product } \\
\text { excretion } \\
( \pm S E)\end{array}$ & $\begin{array}{l}\text { Bile } \\
\text { acids }\end{array}$ & Sterols & $\begin{array}{l}\text { Sterols as } \\
\text { percentage } \\
\text { of total } \\
( \pm S E)\end{array}$ \\
\hline $\begin{array}{l}\text { W. D. M. } \\
\text { M. V. B. } \\
\text { B. B. T. } \\
\text { W. F. B. } \\
\text { O. A. J. }\end{array}$ & $\begin{array}{l}4 \\
4 \\
3 \\
6 \\
4\end{array}$ & $\begin{array}{c}g / \text { day } \\
1.28 \pm 0.23 \\
1.89 \pm 0.13 \\
1.07 \pm 0.11 \\
1.84 \pm 0.36 \\
1.52 \pm 0.10\end{array}$ & $\begin{array}{l}g / \text { day } \\
0.54 \\
0.84 \\
0.24 \\
1.27 \\
1.08\end{array}$ & $\begin{array}{l}\text { g/day } \\
0.74 \\
1.05 \\
0.83 \\
0.57 \\
0.44\end{array}$ & $\begin{array}{c}\% \\
57.7 \pm 3.6 \\
55.4 \pm 0.9 \\
77.4 \pm 1.1 \\
31.2 \pm 4.1 \\
28.8 \pm 2.5\end{array}$ & $\begin{array}{l}4 \\
5 \\
3 \\
5 \\
2\end{array}$ & $\begin{array}{c}g / \text { day } \\
1.65 \pm 0.28 \\
1.97 \pm 0.21 \\
0.66 \pm 0.10 \\
0.80 \pm 0.13 \\
1.29(1.42 ; 1.16)\end{array}$ & $\begin{array}{l}\text { g/day } \\
0.55 \\
0.88 \\
0.10 \\
0.48 \\
0.71\end{array}$ & $\begin{array}{l}\text { g/day } \\
1.10 \\
1.09 \\
0.56 \\
0.32 \\
0.58\end{array}$ & $\begin{array}{c}\% \\
66.8 \pm 4.6 \\
55.5 \pm 1.9 \\
84.6 \pm 1.4 \\
40.6 \pm 2.6 \\
45.2(43.0 ; 47.5)\end{array}$ \\
\hline C. M. B. & 4 & $3.44 \pm 0.27$ & 2.20 & 1.24 & $36.0 \pm 2.3$ & 4 & $5.29 \pm 0.24$ & 2.32 & 2.97 & $56.2 \pm 1.3$ \\
\hline
\end{tabular}

* Coconut oil was used as the saturated fat in all cases. Corn oil was used as the unsaturated fat in subjects B. B. T. and O. A. J.; “"safflower esters" were used in the other subjects. Subjects M. V. B. and C. M. B. received the unsaturated fat before the saturated fat; the order of adminisesters " were used in the other subjects. Subje 
TABLE III

Changes from saturated fat period to unsaturated fat period in fecal excretion and in serum cholesterol level

\begin{tabular}{|c|c|c|c|c|}
\hline Subject & $\begin{array}{l}\text { Total end- } \\
\text { product } \\
\text { excretion }\end{array}$ & $\begin{array}{l}\text { Bile acid } \\
\text { excretion }\end{array}$ & $\begin{array}{l}\text { Sterol ex- } \\
\text { cretion }\end{array}$ & $\begin{array}{c}\text { Serum } \\
\text { cholesterol } \\
\text { level }\end{array}$ \\
\hline $\begin{array}{l}\text { W. D. M. } \\
\text { M. V. B. } \\
\text { B. B. T. } \\
\text { W. F. B. } \\
\text { O. A. J. }\end{array}$ & $\begin{array}{l}\text { g/day } \\
+0.37 \\
+0.08 \\
-0.41^{*} \\
-0.04^{*} \\
-0.23\end{array}$ & $\begin{array}{l}\text { g/day } \\
+0.01 \\
+0.04 \\
-0.14 \\
-0.79 \\
-0.37\end{array}$ & $\begin{array}{c}\text { g/day } \\
+0.36 \\
+0.04 \\
-0.27 \\
-0.25 \\
+0.14\end{array}$ & $\begin{array}{c}m g / 100 m l \\
-257 \\
-175 \\
-118 \\
-110 \\
-24\end{array}$ \\
\hline C. M. B. & $+1.85^{*}$ & +0.12 & +1.73 & -237 \\
\hline
\end{tabular}

* Difference significant at $\mathrm{p}<0.05$ level.

subject to subject, NSF accounting for 28.8 to $85.3 \%$ of total fecal products on identical dietary intakes. However, with the notable exception of C.M.B. the fractional output in NSF form was remarkably constant and characteristic for a given subject and was only slightly influenced by the nature of the dietary fat.

Applying the present methods to a study of one patient undergoing biliary drainage, we confirmed the results of Siperstein and Murray (13), i.e., 87 to $95 \%$ of the radioactivity recovered in bile resided in the bile acid fraction. This gross difference in distribution of radioactivity in bile and feces probably has a twofold origin. First, there is a considerable excretion of cholesterol across the intestinal wall in addition to the excretion of cholesterol in the bile (14). Second, it is well known that as much as 80 to $90 \%$ of the bile acids entering the duodenum are reabsorbed along the small intestine and recirculated. Both of these factors would contribute to the observed relative enrichment of radioactivity in the sterol fraction in the feces compared with the bile. Frantz and his colleagues (15), who have also found in a patient studied by methods similar to those used here a large fraction of the total end-product excretion in fecal sterols, attributed the low sterol contribution to radioactivity in bile reported by Siperstein and Murray (13) to an increase in bile acid turnover due to the presence of the bile fistula. The patient studied here, however, was undergoing only intermittent drainage of small volumes of bile from her T-tube, and there should not have been any drastic increase in bile acid turnover.

The calculations of net bile acid and sterol excretion are based on the assumption that the spe- cific radioactivity of the fecal products parallels that of serum cholesterol after an initial equilibration period. The validity of this assumption was demonstrated explicitly in one subject (see Figure 1). Other investigators have also found that the specific radioactivity of the fecal products closely follows that of the serum cholesterol (9, $10,16)$.

In discussing results, it appears to us necessary to place in a separate category the one patient (C.M.B.) whose total fecal end-product excretion was almost twice that of the patient with the next highest value. If we limit discussion at this point to the other five cases studied, the mean daily output of total end products was $1.52 \mathrm{~g}$ per day on the unsaturated fat diet. These values are substantially higher than the ones obtained by Spritz, Grundy, and Ahrens (17), through direct determination of the various excretory products of cholesterol. The reasons for the apparent discrepancy are not known with certainty. Our values are close to, although slightly higher than, those reported by Moore, Anderson, Keys, and Frantz (16), who also used the isotopic cholesterol labeling method in a series of five young male college students, finding $0.96 \mathrm{~g}$ per day on a butter diet and $1.14 \mathrm{~g}$ per day on a safflower oil diet. The two studies, however, are not strictly comparable, since the age level of the group in the present studies was considerably greater, and the series included patients with hyperlipidemia. Another difference in experimental conditions may be the very high fat content of the formula used in the present study. Since it has been shown that high fat intakes cause an increased fecal fat excretion (18), it is conceivable that larger amounts 
of sterols and bile acids are carried along the intestines when the ingested fat is not fully absorbed. The amounts of fecal solids excreted daily by the patients participating in this study ranged from 15 to $80 \mathrm{~g}$, and therefore in a large number of fecal collections the amounts of solids exceeded the range of 13.6 to $39.1 \mathrm{~g}$ found in feces of subjects on a standard test diet containing some nondigestible solids (18). This suggests that the fecal samples obtained in this study might have had a higher than usual fat content.

The present results focus attention on the large variations in fecal end-product excretion from collection period to collection period. When the study was initiated, collections were made at 2-day intervals, but it quickly became apparent that the variation was so large that no purpose would be served by using short collection periods, and so the 4-day interval was chosen. Even the 4-day averages fluctuated markedly during each diet period, and it is unlikely, therefore, that comparison of single 4-day collections in two diet periods can give valid data in studies of fecal end-product excretion.

In the present series, there was no consistent correlation between the effects of the dietary fats on serum cholesterol levels, on the one hand, and changes in either bile acid or nonsaponifiable lipid excretion, on the other. If the differences between the two periods are evaluated for statistical significance, taking into account the variance in results during each period, only three patients showed a significant change in total end-product excretion. In two it was a decrease and in one an increase on changing to unsaturated fat (Table III). If changes in end-product excretion were limited to the period of transition from one dietary fat to another (i.e., when the serum cholesterol level was changing rapidly), one could calculate on the basis of data in Table III and the approximate pool size of serum cholesterol that such changes in the rate of excretion between the plateau and transition periods should range from 100 to $600 \mathrm{mg}$ per day. Such effects, if present, could have been detected in a number of cases, in spite of the large variation from collection to collection. This type of pattern could not, however, be found in the present series. In short, these studies show that there can be large changes in serum cholesterol induced by changes in dietary fat without a perceptible change in fecal end-product excretion.
For example, in subject M.V.B. over $5 \mathrm{~g}$ of additional cholesterol appeared in the plasma during the transition to saturated fat, yet in the 15-day period involved there was almost no change in rate of SF or NSF excretion. In subjects B.B.T. and W.F.B. about $3 \mathrm{~g}$ of cholesterol disappeared from the plasma during the transition from saturated to unsaturated fat; end-product excretion actually decreased during this period. It must be concluded that in these subjects there was either a decrease in rate of cholesterol biosynthesis or a redistribution of sterol between plasma compartment and tissue storage sites. Similarly, the same data show no evidence indicating an enhancement of endogenous sterol excretion due to the high plant sterol content of corn oil compared to that of coconut oil. Previous work has shown that unsaturated fats elevate the rate of cholesterol synthesis in experimental animals with concomitant shifts of cholesterol into liver (19). Others have reported similar shifts into muscle $(20)$ in animals on feeding unsaturated fats. Evidence of such shifts is quite difficult to demonstrate in man. Carey and Frantz reported no increase in liver cholesterol concentration in subjects fed unsaturated fats before needle biopsy (21). The possibility of transfer of cholesterol to other tissues cannot be ruled out.

The response of patient C.M.B. to dietary oils stands out. Here there was a remarkable increase in an already high rate of end-product excretion from $3.44 \mathrm{~g}$ per day on saturated fat to $5.29 \mathrm{~g}$ per day on the unsaturated fat. Interestingly, the increase was limited to the sterol fraction. The increase in the sterol appearing in the feces more than accounts for the cholesterol disappearing from the plasma compartment. The results in this case, but in this case only, are much like the results reported by Hellman and associates in the single case they studied $(9,10)$. This patient has now been carefully restudied by Ahrens and Grundy (22) both by the indirect radioactivity balance method and by direct measurement of net fecal end-product excretion. On this second occasion, end-product excretion on unsaturated fat was again considerably greater than on saturated fat, a response like that observed in our subject C.M.B. The extra fecal loss of cholesterol and metabolites continued after a new lower steady state plasma cholesterol level was reached, and the losses exceeded the 
amount of cholesterol disappearing from the plasma compartment. Thus, the metabolic responses of these two subjects differ qualitatively from those of all the other subjects studied in these two laboratories. A qualitatively similar response was found by Haust and Beveridge (23) in two patients after their transfer from a fat-free diet to one high in corn oil. The possibility that these patients share a common pattern of sterol metabolism deserves serious consideration.

In recent years several attempts have been made to study the problem at hand. Some have involved measurement of some or all of the excretory products of cholesterol metabolism by direct analysis of feces $(17,24,25)$; others, like the present study, have utilized a "radioactivity balance" method (9, 10, 16). The methodological problems involved in direct fecal analysis have been set forth previously by Sjövall (26). Since the dietary oils studied contain significant amounts of plant sterols that are excreted either as such, or after metabolic breakdown (27-29), adequate interpretation of results of studies depending on direct analysis of fecal metabolites requires differentiation between the excretory products from endogenous and dietary sources. Such a satisfactory differentiation has not been provided, however, in most of these studies. Spritz and his co-workers (17), who have carefully quantified all fecal sterols and bile acids, found no correlation between the degree of saturation of a dietary oil and the rates of excretion of total cholesterol metabolites, in agreement with the results of our study. This conclusion is also consistent with the findings of Hellström and Lindstedt (30) and of Steinberg and associates (31) showing no consistent correlation between the type of dietary fat and the turnover of biliary cholic acid. However, some investigators have reported that unsaturated fats increase bile acid excretion $(24,25)$, others that they enhance sterol excretion $(9,10,23)$. Still other studies show evidence for small changes in both fractions $(16,29)$. The literature is confusing and inconclusive. Although difficulties in methodology may in part explain the confusion, unsuspected variables or biological variation may also contribute to the difficulty in obtaining a consensus. Such variations would detract from the general validity of results obtained with a single or very few patients.
In the present study the observed variability in the responses to changes in dietary fat raises the question as to whether or not these follow any common pattern, in spite of the uniformity in the effect of dietary fat on serum cholesterol levels. One cannot but be impressed by the grossly different patterns in different subjects in the relative contribution of sterols and bile acids to total end-product excretion. This in itself may indicate biological variability that may relate to, or at least attest to, the inhomogeneity of the population in regard to patterns of sterol metabolism and possibly responses to dietary modifications. The number of subjects studied, however, is too limited to allow generalization at this time. Whatever the nature of the mechanism by which dietary fats affect sterol and bile acid metabolism, it may not be uniform, but dictated by the underlying metabolic conditions on which it is superimposed. From our present studies we must conclude that there is at least no necessary and consistent relationship between fat-induced changes in serum cholesterol levels and rates of fecal sterol and bile acid excretion. Any changes that do occur may represent concomitant and not causally related phenomena.

\section{Summary}

The fecal excretion of radioactive sterols and bile acids after intravenous injection of cholesterol$4-{ }^{14} \mathrm{C}$-labeled lipoproteins was studied in six subjects on liquid formula diets providing $60 \%$ of calories as fat. In the feces, nonsaponifiable lipids accounted for $28.8 \%$ to $84.6 \%$ (mean, $52.9 \%$ ) of the radioactivity recovered. The distribution of radioactivity between the sterol-containing fraction and the bile acid fraction was quite reproducible from collection to collection in any individual patient. In five of the six subjects studied the relative output of end products in nonsaponifiable form on diets containing unsaturated fat was somewhat greater than on diets containing saturated fat (average, $69.8 \%$ versus $47.7 \%$ ). This variation was not so great as the large variations in excretion pattern from subject to subject.

It was shown in the one carefully studied patient that the specific radioactivity of fecal sterol and fecal deoxycholic acid closely paralleled the specific radioactivity of serum cholesterol. Assuming a similar relationship to hold on the other pa- 
tients and for all metabolic products, we calculated net excretion of sterols and bile acids from measurements of total radioactivity excreted in these two forms.

On diets containing unsaturated fat, serum cholesterol levels were in all cases lower than on diets containing saturated fat. However, there was no apparent correlation between the effects on serum cholesterol level, on the one hand, and changes in bile acid or sterol excretion, on the other.

The calculated daily sterol excretion in five subjects averaged $0.73 \mathrm{~g}$ per day irrespective of the type of fat in the diet. For bile acid excretion the averages were $0.79 \mathrm{~g}$ per day on the saturated fat diet and 0.54 on the unsaturated fat diet. Neither the differences between these means nor differences in individual subjects by paired data analysis were statistically significant. The sixth subject appeared to be unique, having a mean daily bile acid output on the saturated fat diet of $2.20 \mathrm{~g}$, almost twice the next highest value observed in the group as a whole. This high excretion did not change significantly on switching to unsaturated fat (2.32 $\mathrm{g}$ per day). This subject's daily sterol output on saturated fat was $1.24 \mathrm{~g}$ per day and increased strikingly to $2.98 \mathrm{~g}$ per day on unsaturated fat.

For the group as a whole, however, these studies fail to reveal any consistent relation between fecal bile acid or sterol excretion changes and changes in serum cholesterol concentrations induced by dietary fats.

\section{References}

1. Avigan, J., and D. Steinberg. Metabolism and excretion of cholesterol in man. Fed. Proc. 1959, 18, 5.

2. Ahrens, E. H., Jr., V. P. Dole, and D. H. Blankenhorn. The use of orally-fed liquid formulas in metabolic studies. Amer. J. clin. Nutr. 1954, 2, 336.

3. Avigan, J. A method for incorporating cholesterol and other lipides into serum lipoproteins in vitro. J. biol. Chem. 1959, 234, 787.

4. Sperry, W. M., and M. Webb. A revision of the Schoenheimer-Sperry method for cholesterol determination. J. biol. Chem. 1950, 187, 97.

5. Stewart, C. P., and E. B. Hendry. The phospholipins of blood. Biochem. J. 1935, 29, 1683.

6. Bragdon, J. H. Colorimetric determination of blood lipides. J. biol. Chem. 1951, 190, 513.

7. Jover, A., and R. S. Gordon, Jr. Procedure for quantitative analysis of feces with special reference to fecal fatty acids. J. Lab. clin. Med. 1962, 59, 878.
8. Hellman, L., R. S. Rosenfeld, M. L. Eidinoff, D. K. Fukushima, T. F. Gallagher, C. Wang, and D. Adlersberg. Isotopic studies of plasma cholesterol of endogenous and exogenous origins. J. clin. Invest. 1955, 34, 48.

9. Hellman, L., R. S. Rosenfeld, W. Insull, Jr., and E. H. Ahrens, Jr. Intestinal excretion of cholesterol: a mechanism for regulation of plasma levels (abstract). J. clin. Invest. 1957, 36, 898.

10. Hellman, L., and R. S. Rosenfeld. Isotopic studies of cholesterol metabolism in man in Hormones and Atherosclerosis. New York, Academic Press, 1959, p. 157.

11. Mosbach, E. H., C. Zomzely, and F. E. Kendall. Separation of bile acids by column-partition chromatography. Arch. Biochem. 1954, 48, 95.

12. Lindstedt, S. Equilibration of dietary cholesterol and bile acids in man. Clin. chim. Acta 1962, 7, 1.

13. Siperstein, M. D., and A. W. Murray. Cholesterol metabolism in man. J. clin. Invest. 1955, 34, 1449.

14. Rosenfeld, R. S., and L. Hellman. The endogenous precursor of fecal sterol. Fed. Proc. 1959, 18, 312.

15. Frantz, I. D., Jr., J. B. Carey, Jr., R. Moss, J. F. Eckert, M. Goldfarb, and H. I. Katz. Observations on the turnover of cholesterol in a human subject. Minn. Med. 1958, 41, 157.

16. Moore, R. B., J. T. Anderson, A. Keys, and I. D. Frantz, Jr. Effect of dietary fat on the fecal excretion of cholesterol and its degradation products in human subjects (abstract). J. Lab. clin. Med. 1962, 60, 1000.

17. Spritz, N., S. Grundy, and E. H. Ahrens, Jr. Sterol balance in man as plasma cholesterol concentrations are altered by exchange of dietary fats. J. clin. Invest. 1965, 44, 1432.

18. Wollaeger, E.E., M. W. Comfort, and A. E. Osterberg. Total solids, fat and nitrogen in the feces: III. A study of normal persons taking a test diet containing a moderate amount of fat; comparison with results obtained with normal persons taking a test diet containing a large amount of fat. Gastroenterology 1947, 9, 272.

19. Avigan, J., and D. Steinberg. Effect of saturated and unsaturated fat on cholesterol metabolism in the rat. Proc. Soc. exp. Biol. (N. Y.) 1958, 97, 814.

20. Bieberdorf, F. A., and J. D. Wilson. Influence of unsaturated fat on cholesterol- $\mathrm{C}^{\mathbf{1 4}}$ metabolism in the isotopic steady state in the rabbit (abstract). Clin. Res. 1964, 12, 262.

21. Carey, J. B., Jr., and I. D. Frantz, Jr. The effect of corn oil and hydrogenated coconut oil on the liver cholesterol content in human subjects (abstract). Circulation 1960, 22, 661.

22. Ahrens, E. H., Jr., and S. Grundy. Personal communication.

23. Haust, H. L., and J. M. R. Beveridge. Type and quantity of $3 \beta$-hydroxysterols excreted by subjects subsisting on formula rations high in corn oil. J. Nutr. 1963, 81, 13. 
24. Gordon, H., B. Lewis, L. Eales, and J. F. Brock. Dietary fat and cholesterol metabolism. Faecal elimination of bile acids and other lipids. Lancet 1957, 2, 1299.

25. Haust, H. L., and J. M. R. Beveridge. Effect of varying type and quantity of dietary fat on the fecal excretion of bile acids in humans subsisting on formula diets. Arch. Biochem. 1958, 78, 367.

26. Sjövall, J. Separation and determination of bile acids in Methods of Biochemical Analysis. New York, Interscience, 1964, vol. 12, p. 97.

27. Werbin, H., I. L. Chaikoff, and E. E. Jones. The metabolism of $\mathrm{H}^{3}-\beta$-sitosterol in the guinea pig: its conversion to urinary cortisol. J. biol. Chem. $1960,235,1629$.
28. Swell, L., and C. R. Treadwell. Metabolic fate of injected C $\mathrm{C}^{14}$-phytosterols. Proc. Soc. exp. Biol. (N. Y.) 1961, 108, 810.

29. Goldsmith, G. A., J. G. Hamilton, and O. N. Miller. Lowering of serum lipid concentrations. Mechanisms used by unsaturated fats, nicotinic acid and neomycin: excretion of sterols and bile acids. Arch. intern. Med. 1960, 105, 512.

30. Hellström, K., and S. Lindstedt. Unpublished results. 31. Lindstedt, S., J. Avigan, DeW. S. Goodman, J. Sjövall, and D. Steinberg. The effect of dietary fat on the turnover of cholic acid and on the composition of the biliary bile acids in man. J. clin. Invest. 1965, 44, 1754. 